
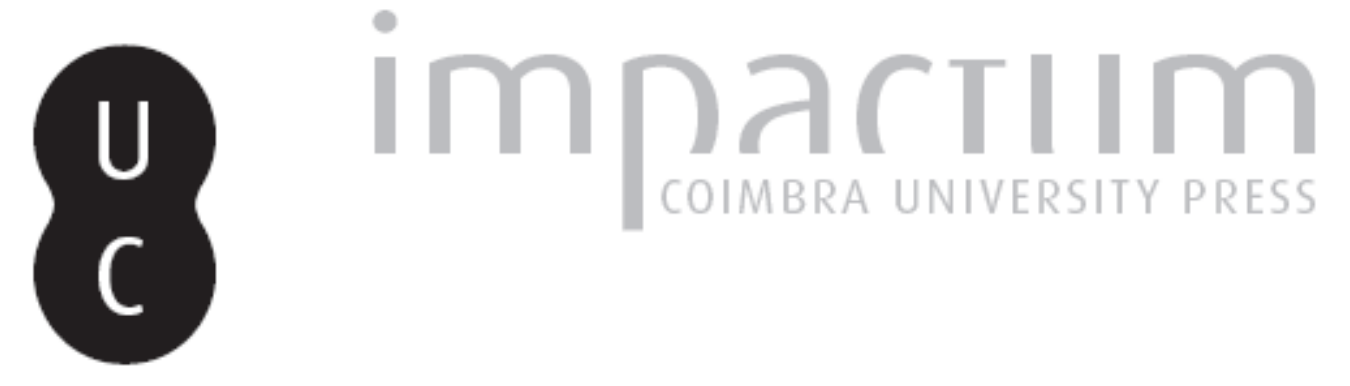

\title{
Ciência e Humanismo: a visão da ciência de Erwin Schrödinger
}

Autor(es): $\quad$ Fiolhais, Carlos

Publicado por: Imprensa da Universidade de Coimbra

URL persistente:

URI:http://hdl.handle.net/10316.2/37830

DOI:

DOI:http://dx.doi.org/10.14195/0870-4112_3-1_6

Accessed : $\quad$ 26-Apr-2023 01:46:53

A navegação consulta e descarregamento dos títulos inseridos nas Bibliotecas Digitais UC Digitalis, UC Pombalina e UC Impactum, pressupõem a aceitação plena e sem reservas dos Termos e Condições de Uso destas Bibliotecas Digitais, disponíveis em https://digitalis.uc.pt/pt-pt/termos.

Conforme exposto nos referidos Termos e Condições de Uso, o descarregamento de títulos de acesso restrito requer uma licença válida de autorização devendo o utilizador aceder ao(s) documento(s) a partir de um endereço de IP da instituição detentora da supramencionada licença.

Ao utilizador é apenas permitido o descarregamento para uso pessoal, pelo que o emprego do(s) título(s) descarregado(s) para outro fim, designadamente comercial, carece de autorização do respetivo autor ou editor da obra.

Na medida em que todas as obras da UC Digitalis se encontram protegidas pelo Código do Direito de Autor e Direitos Conexos e demais legislação aplicável, toda a cópia, parcial ou total, deste documento, nos casos em que é legalmente admitida, deverá conter ou fazer-se acompanhar por este aviso.

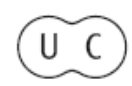




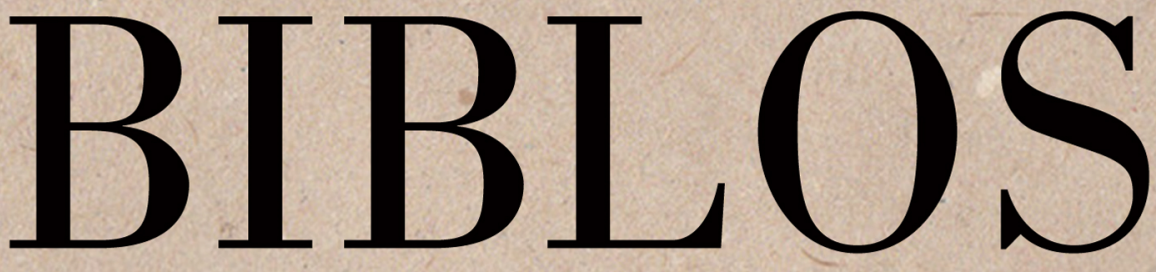

Revista da Faculdade de Letras da Universidade de Coimbra

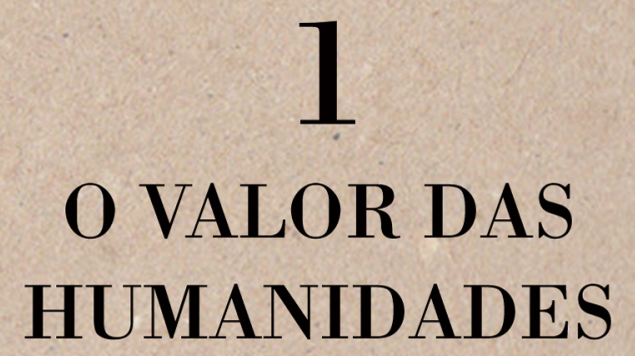

NÚMERO 1, 2015

3. ${ }^{\text {a }}$ SERIE 


\title{
CIÊNCIA E HUMANISMO. A VISÃO DA CIÊNCIA DE ERWIN SCHRÖDINGER Science and Humanism. The vision of Erwin Schrödinger
}

\author{
CARLOS FIOLHAIS \\ tcarlos@uc.pt \\ Departamento e Centro de Física da Faculdade de Ciências e Tecnologia \\ Universidade de Coimbra
}

DOI

http://dx.doi.org/10.14195/0870-4112_3-1_6

Recebido em setembro de 2014

Aprovado em janeiro de 2015

Biblos. Número 1, $2015 \cdot 3$. $^{\text {a série }}$ pp. $127-151$ 


\title{
CARLOS FIOLHAIS
}

\section{RESUMO.}

Erwin Schrödinger, o físico austríaco, que foi um dos principais autores da física quântica, realizou em 1950 uma série de conferências intituladas Ciência e humanismo, que estão traduzidas em português. Analisamos aqui a sua visão da ciência como parte do esforço do ser humano em conhecer-se. Debatemos a sua perspectiva da unidade das ciências, a relação entre ciência e técnica, as raízes profundas do pensamento científico na Antiguidade Grega e, além disso, a interacçăo da ciência com a filosofia e a religiāo. Expressamos a opiniāo de que uma boa parte das suas reflexōes são relevantes nos dias de hoje, quando se fala da crise do humanismo. Mais humanismo significa mais e melhor ciência, o que significa progresso na integração de diferentes ramos do conhecimento humano.

Palavras-chave: Schrödinger; Física Quântica; Ciência; Humanismo; Técnica; Grécia Antiga

\begin{abstract}
.
In 1950, Erwin Schrödinger, the Austrian physicist who was one of principal proponents of quantum physics, gave a series of lectures entitled Science and Humanism. It has been translated into Portuguese. This essay analyzes his perpective of science as a part of the effort of the human being to know him/ herself. We discuss his vision of the unity of sciences, the relation between science and technique, the deep roots of scientific thinking in Greek Antiquity and, in addition, the interplay of science with philosophy and religion. We argue that a great part of Schrödinger's reflections are still relevant today, at a time when it has become usual to speak of the crisis of humanism. More humanism means more and better science, and that means progress in the integration of different branches of human knowledge.
\end{abstract}

Keywords: Schrödinger; Quantum Physics; Science; Humanism; Technique; Greek Antiquity 
É muito difícil, nos tempos que correm e atendendo a todos os tempos que ocorreram desde que há escrita, ser autor de um título original. A Biblioteca de Babel do escritor argentino Jorge Luis Borges ainda náo existe na realidade, mas vamos ficando com uma aproximação cada vez melhor.

Assim, confesso que fui buscar o título que encima o presente escrito a um ensaio do físico austríaco Erwin Schrödinger (1887-1961), o autor da mais famosa equação da teoria quântica, que preside aos fenómenos microscópicos da física e da química, e um dos nomes maiores da ciência do século xx. Em 1950 ele foi convidado a proferir um conjunto de liçóes no Dublin Institute for Advanced Studies, na Irlanda, onde estava exilado devido à ocupação nazi da Europa Central (Schrödinger tinha tomado posiçóes anti-nazis, em particular contra a perseguição aos judeus). O texto dessas liçóes está incluído no livro Ciência e humanismo, saído em 1952 (Schrödinger 1952) e republicado em 1996 (Schrödinger 1996), antecedido do texto A natureza e os gregos, também resultado de conferências públicas, desta vez proferidas no University College de Londres em 1948, com um prefácio do físico-matemático da Universidade de Oxford Roger Penrose (n. 1931). Esta última obra está traduzida em português, tendo saído entre nós com o título A natureza e os gregos e Ciência e humanismo em 1999 (Schrödinger 1999). Se for necessária uma justificação para ir buscar o título a esta obra de Schrödinger, direi que é um dos livros da minha biblioteca que saco com mais frequência da estante sempre que sou chamado a reflectir sobre o objectivo, o significado e o valor da ciência. E foi isto precisamente o que fiz logo que recebi o desafio para escrever sobre Ciências e Humanidades para este número da Biblos.

Lembrava-me de um parágrafo sobre o valor da ciência que aqui transcrevo para que mais leitores se venham a lembrar:

Podem perguntar — têm de me perguntar agora: Qual é, então, na sua opiniāo, o valor da ciência natural? Respondo: $\mathrm{O}$ seu âmbito, objectivo e valor são os mesmos que os de qualquer outro ramo do conhecimento humano. Ou melhor, nenhum deles por si só, apenas a união de todos eles, tem qualquer âmbito ou valor e isso acontece muito simplesmente porque 
representa a obediência ao comando da divindade délfica: gnothi seauton, conhece-te a ti próprio.

(Schrödinger 1999: 99)

Sobre o propósito e a relevância da ciência tudo está dito neste aforismo atribuído a vários autores gregos: Conhece-te a ti mesmo (transliterando o grego, gnothi seauton), que terá sido inscrito no pátio do Templo de Apolo em Delfos. O conhecimento do mundo, que inclui naturalmente o homem, nada mais afinal é do que conhecimento do homem.

\section{BREVE BIOGRAFIA DE SCHRÖDINGER}

Erwin Schrödinger nasceu em Viena em 1887, filho de um botânico e industrial e neto pela parte da mãe, que era semi-austríaca e semi-inglesa, de um professor de Química da Technische Hochschule Vienna ${ }^{1}$. O pai era católico e a mãe luterana. Depois de ter feito estudos domésticos até aos 11 anos, foi aluno brilhante do Akademisches Gymnasium em Viena, para depois entrar na Universidade de Viena, onde aprendeu Física. Obteve o doutoramento em 1910, tendo ingressado como assistente na instituição onde efectuara estudos superiores. Os seus primeiros trabalhos foram de índole experimental. Pouco depois de ter obtido a habilitação para a docência (1914) foi chamado a servir a Áustria-Hungria na Primeira Guerra Mundial, o que fez sem sobressaltos de maior como oficial de artilharia em posiçóes do norte de Itália e na própria Áustria. Em 1920, ano em que se casou, tornou-se assistente de outro grande físico austríaco, Wilhelm Wien (1864-1928), na Universidade de Jena, na Alemanha. Não demorou até obter um lugar em Stuttgart e, em 1921, ficou professor em Breslau, na Polónia, donde logo mudou para Zurique.

Aí começou o período mais produtivo da sua carreira. Em 1926, quando ensinava Física Teórica na Universidade de Zurique, na Suíça, deu uma contri-

\footnotetext{
As principais biografias são Moore 1992, 2003, Gribbin 2012; em português Piza 2003.
} 
buição fundamental à teoria quântica, que tinha emergido no início do século, ao propor num artigo saído nos renomados Annalen der Physik (intitulado "Quantisierung als Eigenwertproblem", "A quantização como um problema de valores próprios" (Schrödinger 1926), a famosa equação que tem hoje o seu nome, tendo mostrado que ela funcionava na perfeição para calcular os níveis de energia do átomo de hidrogénio. Noutros três trabalhos saídos nesse seu annus mirabilis mostrou outras aplicaçôes, designadamente ao oscilador harmónico e ao rotor, e uma generalizaçáo para o caso dependente do tempo. Partiu da leitura de um artigo do físico suíço, mais tarde também norte-americano, de origem alemã, Albert Einstein (1879-1955), no qual este citava o trabalho do francês Louis de Broglie (1892-1987) relativo à dualidade onda-corpúsculo para o electrão: se era certo que uma partícula material como o electrão tinha de ser encarada como corpúsculo em certas circunstâncias, noutras tinha de ser vista como onda, tal como sucedia com a própria radiação, que se manifestava por vezes como onda e noutras vezes como corpúsculo (Einstein tinha descoberto em 1905 que, no efeito fotoeléctrico, a luz devia ser vista como um conjunto de "grâos", os fotóes). Ora, se os electróes eram descritos como ondas, deveria existir uma equação de onda. Schrödinger encontrou essa equação nas férias de Natal de 1925, que passou na estância de Arosa, não longe de Zurique, na companhia náo da sua esposa mas de uma amante cujo nome permanece incógnito (a relaçáo conjugal de Schrödinger era muito aberta, tendo ele tido ao longo da vida suas várias amantes, por vezes co-habitando com ele e a mulher; Schrödinger fazia registos das suas aventuras amorosas, mas, como falta o livro de 1925, desconhece-se quem terá sido a sua musa inspiradora). O trabalho do físico de 39 anos foi recebido com agrado tanto por Einstein como por Max Planck (1859-1947), o fundador da teoria quântica. Já não o foi por Werner Heisenberg (1901-1976), o jovem alemáo que tinha criado pouco antes a "mecânica das matrizes" para explicar os fenómenos microscópicos, que se veio a revelar perfeitamente equivalente à chamada "mecânica ondulatória" de Schrödinger. O alemão Max Born (1882-1970) forneceu ainda em 1926 o significado da onda, designada pela letra grega $p s i$, que surge na equação de Schrödinger: tratava-se de uma onda de probabilidade, isto é, só poderíamos conhecer a posiçẫo do electrão indicando uma certa probabilidade. Essa in- 
terpretação de probabilidade, adaptada pelo físico dinamarquês Niels Bohr (1885-1962), que tinha em 1913 proposto um modelo quântico simples para o átomo de hidrogénio, e, mais em geral, pela chamada "escola de Copenhaga", que foi ganhando terreno na comunidade científica, não foi bem aceite nem por Einstein nem por Schrödinger. A questão maior é o chamado problema da medida: para descrever uma partícula quântica usamos uma onda de probabilidade, mas detectamos essa partícula num certo sítio; portanto, a onda tem de alguma maneira de colapsar no processo de medida, sob a influência do observador. Para combater esse tipo de ideias, que se opunham à tradicional separação entre observador e objecto, Schrödinger viria a criar em 1935 uma experiência mental (Gedankenexperimente) que ficou famosa: o "gato de Schrödinger" é um felino encerrado numa caixa que tem uma certa probabilidade de estar vivo e outra de estar morto, uma vez que a sua sorte depende de um dispositivo quântico. Será que ele morre instantaneamente quando abrimos a caixa para o observar? A explicação moderna é estatística: se tivermos um ensemble numeroso de caixas com gatos, num certo número delas ele estará morto e noutras estará vivo, tomando nós conhecimento da situação apenas no momento da observação.

Graças ao impacto do seu trabalho, Schrödinger conseguiu em 1927 um lugar na Universidade de Berlim, tornando-se colega de Einstein ao ocupar a cátedra de Max Planck, entretanto jubilado. Permaneceu aí até 1933. Depois, com o advento do nacional-socialismo na Alemanha, passou para a Universidade de Oxford. Nesse mesmo ano de 1933 recebeu o Prémio Nobel da Física juntamente com o inglês Paul Dirac (1902-1984), pela descoberta da sua equação (Dirac conseguiu uma equação mais geral, por satisfazer as exigências da teoria da relatividade restrita). Em Oxford não foi fácil a aceitação da sua bigamia (de facto, a sua amante, de quem tinha um filho, era casada com um outro homem). Em 1934 ensinou na Universidade de Princeton, nos Estados Unidos, mas, convidado para lá ficar, declinou o convite. Tal como em Oxford, não foi fácil a aceitação da sua heterodoxa situação familiar. No Verão de 1934 Schrödinger deu um curso de Verão em Santander, Espanha, e no dia seguinte fez um tour, em parte turístico, por Espanha (Sanchez-Rón 1992). Recebeu um convite para um lugar na Universidade de Madrid, que 
recusou (um convite semelhante tinha sido endereçado a Einstein em 1933). Em 1936 acabou por se transferir para a Universidade de Graz, no seu país natal, o que mais tarde reconheceu ter sido um erro, pois em 1938 foi apanhado pelo Anschluss: aí teve de pagar o preço pelas suas posiçóes anti-nazis e por ter abandonado a Alemanha em 1933. A Universidade de Graz passou na época a chamar-se Adolf Hitler (que, lembre-se, era austríaco). Ainda ensaiou uma retractação, algo ambígua, da qual mais tarde se haveria de arrepender amargamente, mas de nada lhe valeu. Foi obrigado a fugir com a mulher de comboio para Itália. Iniciou entáo uma odisseia pela Europa, tendo passado pelo Vaticano (foi membro da Academia de Ciências do Vaticano), pelo Reino Unido (Oxford de novo) e pela Bélgica (Gent). Em 1940, fixou-se finalmente em Dublin, à frente do então criado Instituto de Estudos Avançados, a convite do primeiro-ministro Eamon de Valera (1882-1975), um político que tinha estudado Matemática. Iniciou-se assim um outro período fértil da sua vida, que durou 16 anos: tornou-se um reputado professor, convidado a fazer uma série de conferências sobre física e não só. Cada vez mais Schrödinger gostava de falar sobre assuntos filosóficos, que estavam de resto em contacto íntimo com as novidades da teoria quântica. Foi em Dublin que Schrödinger proferiu em 1943 as suas conferências intituladas $O$ que é a vida?, que resultaram na edição no ano seguinte que é talvez o seu livro mais famoso (Schrödinger 1944), no qual forneceu um contributo essencial para a interpretação físico-química dos fenómenos biológicos (ver a tradução portuguesa, Schrödinger 1989). Para ele, e tinha inteira razão, todos os fenómenos da vida, incluindo a hereditariedade, eram resultado de leis físico-químicas. Em 1948, pouco depois de se ter tornado cidadão irlandês sem perder a nacionalidade austríaca, proferiu três conferências públicas em Londres sobre A natureza e os gregos e em 1950 quatro conferências também públicas em Dublin sobre Ciência e humanismo. Só em 1956, a pedido insistente de amigos e conhecidos, Schrödinger voltou à sua alma mater, a Universidade de Viena, onde lhe foi concedida uma cátedra $a d$ personam e, logo a seguir, o título de professor emérito. Em Viena, convidado a falar sobre energia nuclear num encontro internacional sobre esse tema, preferiu falar sobre filosofia. Nos anos finais da sua vida abandonou de vez a dualidade onda-partícula para afirmar a existência apenas e tão só de ondas, 
posição que não poderia deixar de escandalizar os físicos da ortodoxia quântica. Nunca aceitou a ligação entre o observador e o observado, como é defendida pela "escola de Copenhaga", preferindo como Einstein uma posiçấo realista, isto é, para ele a realidade deveria existir independentemente do observador e da observação. Declarou um dia num diálogo com Bohr: "Se todos estes saltos quânticos acabarem realmente por ficar, tenho de me lamentar de ter tido alguma coisa a ver com ela" (Kumar 2008: 223; trad. do autor).

Schrödinger faleceu em 1961 de tuberculose, uma doença de que padeceu várias vezes. Foi sepultado em Alpbach, uma aldeia dos Alpes no seu país natal (a sua equaçáo está numa modesta placa na campa, onde também jaz a sua mulher, companheira de vida, apesar de o divórcio ter sido sempre um tema recorrente). $\mathrm{O}$ padre católico que deveria presidir à cerimónia fúnebre perdeu as hesitaçóes que tinha quanto à realizaçáo do funeral quando lhe foi comunicado que Schrödinger, cuja vida pessoal não se regulava, como foi dito, pelos cânones da moral cristã, era membro da Academia Pontifícia das Ciências.

Era poliglota: dominava o alemão e o inglês, de infância, e falava correntemente francês, italiano e castelhano (aprendeu esta língua para visitar Espanha). Sabia os rudimentos de línguas clássicas por ter frequentado o liceu clássico. Cultivou a poesia, porque lhe era impossível expressar certas emoçóes de outro modo (publicou em 1949 o livro Gedichte (Schrödinger 1949), de qualidade literária muito discutível). Apreciava a arte, o teatro mais do que a música. Do ponto de vista filosófico, para além dos autores antigos, foi influenciado pelo alemão Arthur Schopenhauer (1788-1860) e, entre os pensadores seus contemporâneos, pelo britânico Bertrand Russel (1872-1970), bem como pelos espanhóis José Ortega y Gasset (1883-1955) e Miguel de Unamuno (1864-1936), e, numa fase mais tardia da sua vida, por filosofias hindus. Adiante falaremos das suas particularidades em matéria de religião.

\section{CIÊNCIA E HUMANISMO SEGUNDO SCHRÖDINGER}

$\mathrm{Na}$ senda do livro de Schrödinger ao qual retirei o título, julgo que a primeira coisa que há a dizer sobre Ciência e Humanismo é que os dois conceitos não são de modo nenhum opostos. A ciência é uma forma de humanismo. É necessário 
uma e outra vez reafirmar o óbvio, pois nem sempre é visto como óbvio: a ciência é feita pelo homem e para o homem. É certo que a generalidade das pessoas, quando pensa em ciência, associa-a imediatamente a descobertas, invençóes e à transformaçáo da sociedade que umas e outras abundantemente permitem. Mas o valor mais fundamental da ciência não reside, como essa maioria pensa, na sua utilidade material para a sociedade, mas sim no acrescento de humanismo que ela permite. No fundo, a ciência mais não faz do que procurar responder à interrogação da Antiguidade Clássica, "quem somos?", a qual podemos explicitar: "Donde vimos e para onde vamos?". Se a vida tem algum sentido, ele poderá ser o de procurar responder a estas permanentes questôes, que desde os gregos têm atravessado toda a história suscitando respostas que se vão acumulando. Damos, de novo, voz ao físico Schrödinger, no início do seu ensaio sobre Ciência e humanismo:

Nasço e faço parte de um ambiente — não sei de onde vim nem para onde vou, nem quem sou. Esta é a minha situação, tal como é a vossa. Tal como é a de cada um de vós. O facto de desde sempre todas as pessoas terem vivido e continuarem a viver nesta situação não me diz nada. A nossa questão premente tem a ver com a origem e com o destino - mas tudo o que podemos investigar é o ambiente actual. Por isso temos necessidade de descobrirmos tanto quanto pudermos acerca dele. E esse esforço representa a ciência, a educação, o conhecimento. Esta é a fonte verdadeira das diligências espirituais do homem. Tentamos descobrir tanto quanto podemos acerca do ambiente circundante espacial e temporal do local em que nascemos. E, enquanto tentamos, deleitamo-nos com isso, consideramos que essa é uma actividade extremamente interessante (será que esse não pode ser afinal o objectivo pelo qual estamos aqui?).

(Schrödinger 1999: 99)

Talvez esta posição de grande abertura filosófica seja inesperada, ou talvez não seja, dadas as bem conhecidas ligações entre a física e a filosofia. Schrödinger foi, claramente, além de físico, um filósofo (cerca de uma dezena dos seus livros, em geral colecçôes de ensaios, são, de facto, mais de filosofia do que de 
física). Na citação anterior está todo um programa filosófico, no sentido em que explicita a razão de ser da ciência. A frase "Por isso temos necessidade de descobrir tudo quanto pudermos acerca do ambiente actual" ressoa ao imperativo categórico gravado na lápide no cemitério de Göttingen do matemático alemão David Hilbert (1862-1943): Wir mussen wissen. Wir werden wissen ("Temos de saber. Havemos de saber"). A aquisição de conhecimento a respeito do mundo é uma necessidade humana, uma das maiores, senão mesmo a maior das capacidades humanas, de onde se conclui que a ciência é uma actividade humana, muito humana. A ciência é uma forma de humanismo. O conhecimento de tipo científico estará até a montante de outras necessidades humanas já que, para o físico austríaco, ele é a "fonte verdadeira das diligências espirituais do homem”, quer dizer, as inquietaçôes metafísicas surgem a partir da experiência do mundo empírico. Por último, Schrödinger, que pode ser considerado um hedonista, refere o prazer proporcionado pela procura de conhecimento: no parágrafo final, modestamente colocado entre parêntesis, deixa, para quem a queira apanhar, uma especulação sobre o sentido da vida, um dos problemas maiores da metafísica.

Em 1943, Schrödinger foi o primeiro, no seu ensaio O que é a vida, que conheceu ampla difusão, a propor que a matéria viva, nas suas mais diversas manifestações, não era mais do que física e química. Era no mundo molecular, nessa altura em larga medida por explorar, que tinham de ser encontrados os fundamentos da genética. $\mathrm{O}$ animismo ficou com essa obra definitivamente enterrado.

O físico inglês Francis Crick (1916-2004) e o biólogo norte-americano James Watson (n. 1928), leitores desse livro, haveriam de encontrar, com a ajuda de experiências de difracção de raios X, em 1953, a estrutura em dupla hélice do ácido desoxiribonucleico, $\mathrm{ADN}$, repositório da informação genética. E os últimos anos de Schrödinger foram marcados, decerto para contentamento deste, pelo desenvolvimento vertiginoso das ciências biológicas e, com base nelas, da medicina. $\mathrm{O}$ segredo da vida deixou de ser assim tão secreto à medida que se fazia a leitura da informação contida no genoma para o fabrico da maquinaria celular. A teoria quântica está, portanto, na ascendência directa da biologia molecular. 
Poderemos hoje dizer que a razão da omnipresença dos seres humanos na Terra e o poder que o saber lhes conferiu sobre o ambiente tem a ver com o facto de a selecção natural ter proporcionado ao homo sapiens sapiens especiais capacidades cognitivas. Saber é poder - já tinha dito o filósofo inglês Francis Bacon, contemporâneo da Revolução Científica (Fiolhais 1997). Conhecendo cada vez melhor o nosso ambiente, poderemos não só furtar-nos a perigos dele provenientes mas também, concretizar uma vida o mais confortável possível. A selecção teve a virtude de associar o prazer à conquista de conhecimento, fazendo com que o alargamento das capacidades mentais seja uma necessidade biológica.

Tal como o ser humano, tendo múltiplas dimensôes, tem uma unidade indesmentível, também o conhecimento deve ser unido. Para Schrödinger, o conhecimento forma um todo, sendo sem valor o conhecimento especializado que não se consiga ligar a outras parcelas de conhecimento. Tal é afirmado logo na sequência da citação anterior:

Parece simples e evidente, e contudo necessita de ser dito: o conhecimento isolado obtido por um grupo de especialistas num campo restrito não tem por si qualquer valor. Mas apenas quando se concretiza a sua síntese com todo o restante conhecimento, e apenas desde que contribua de forma efectiva nessa síntese para conseguir responder à questão: "Quem somos nós?" (Schrödinger 1999: 99-100)

Como havia uma só questáo, as várias respostas da ciência tinham de ser unidas. No seu ensaio tinha começado por criticar a ideia utilitária da ciência, oferecendo três tipos de argumento.

(1) Pese embora a diversidade de metodologias, a unidade das ciências (na língua alemã ciência é Wissenschaft, que vem de Wissen, saber) obriga ao tratamento no mesmo plano das várias ciências, tanto ciências exactas e naturais como a física, a química ou a biologia, que permitem obter aplicaçôes práticas para a nossa vida, como ciências sociais tais como a história ou a filosofia, das quais 
parecem não resultar benefícios materiais mas apenas espirituais. As ciências exactas e naturais são tão ciências como as ciências sociais e humanas. Escreveu a este propósito o sábio austríaco:

Pensem no estudo ou na investigação desenvolvida na história, nas línguas, na filosofia, na geografia - ou na história da música, pintura, escultura, arquitectura - ou na arqueologia e na pré-história. Ninguém gostaria de associar a estas actividades, como seu objectivo principal, a melhoria prática das condiçôes da sociedade humana, apesar de a melhoria dessas condiçóes advir, muito frequentemente, dessas actividades.

(Schrödinger 1999: 98)

(2) Por outro lado, boa parte das próprias ciências naturais não têm qualquer relevância para a vida dos terrestres: Schrödinger nomeia a astrofísica, a cosmologia e alguns ramos da geofísica. No entanto, as pessoas revelam-se em geral sedentas pelas notícias que a ciência destes domínios lhes traz. Hoje em dia as notícias de descobertas no espaço são das que mais atençôes atraem, na imprensa, na televisão ou na internet. Há, de facto, um imaginário nos céus que nos atrai. O que há para além do sistema solar? E da nossa Galáxia? O que são afinal as estrelas? O que é uma supernova? O que é um buraco negro? Houve um início do Universo? O Universo é eterno? As duas últimas questôes foram durante muito tempo da esfera do religioso e hoje, embora mantenham conotações religiosas, são questôes que cabem completamente na esfera da ciência, uma vez que esta lhes responde de uma forma simples: o Universo começou há cerca de 13,7 mil milhôes de anos, com o evento que designamos por big bang, e, não sendo eterno para trás, é provavelmente eterno para a frente.

(3) Por último, é duvidoso que a felicidade da espécie humana tenha resultado sempre das realizaçóes tecnológicas que se seguiram ao progresso da ciência. Schrödinger foi taxativo: "Considero que é extremamente duvidoso saber se a felicidade da raça humana tem sido melhorada 
graças às evoluçóes técnicas e industriais que se seguiram ao rápido desenvolvimento da ciência natural" (Schrödinger 1999: 98).

Isto é, nem todas as utilidades da ciência são necessariamente boas para o homem, entrando na escolha dessas utilidades um juízo de valor que naturalmente transcende a ciência. Se a ciência é uma dimensão do homem, uma parte importante do humanismo, ela não é obviamente a única dimensão do homem, não é todo o humanismo. Há, designadamente, escolhas éticas a fazer no que respeita às potenciais realizaçóes da ciência. A ciência pode informar a respeito das possibilidades disponíveis à Humanidade, mas é um erro pensar que cabe à comunidade dos cientistas efectuar essas escolhas. Nas sociedades democráticas as decisóes devem ser feitas por todos, tanto quanto possível em condiçóes de igualdade.

Schrödinger não está evidentemente sozinho na sua apreciação do valor imaterial da ciência. Em virtude desse valor, tem sido evidenciado o paralelismo entre a ciência e a arte. O matemático francês Henri Poincaré (1854-1912) exaltou em igual medida a ciência e a arte no seu livro $O$ valor da ciência: "Não é senão pela Ciência e pela Arte que valem as civilizações" (Poincaré 1995). Noutro livro, Ciência e método, descreveu a relação artística do homem com o mundo natural, microscópico ou macroscópico, do seguinte modo:

O cientista não estuda a natureza porque tal é útil; estuda-a porque tem prazer nisso e tem prazer nisso porque ela é bela. Se a natureza não fosse bela, não valeria a pena conhecê-la nem a vida valeria a pena ser vivida. Pretendo falar a beleza íntima que provém da ordem harmoniosa das partes e que pode ser compreendida por uma inteligência pura. (...) É porque a simplicidade e a vastidão são ambos belas que procuramos de preferência factos simples e factos vastos, que tomamos prazer em seguir ora os gigantescos percursos das estrelas ora os astros, em escrutinar com um microscópio a pequenez prodigiosa que é também uma vastidão ora em procurar nas eras geológicas os traços de um passado remoto que por isso nos atrai.

(Poincaré 1920: 15-16; trad. do autor) 
Deduz-se que Poincaré não teria sorte nenhuma com as actuais agências financiadoras de ciência, com toda a evidência muito mais preocupadas com os aspectos utilitários do que estéticos. O jornalista e escritor britânico John William Sullivan, um biógrafo de Newton e Beethoven, interessado por isso tanto pela origem da criação científica como pela da criação artística, resumiu em 1919 assim as posições de Poincaré sobre a beleza do mundo: "A medida em que a ciência falha em ser arte é a medida em que é incompleta como ciência" (apud Chandrasekhar 1987: 60; trad. do autor).

$\mathrm{Na}$ mesma linha o grande físico suíço e norte-americano de origem alemã Albert Einstein escreveu em 1935, num texto incluído no seu livro Como eu vejo a ciência, a religião e o mundo, que a ciência detinha um duplo poder sobre os seres humanos:

A ciência afecta os assuntos humanos de duas maneiras. A primeira é bem conhecida de toda a gente. Directamente, e mais ainda de forma indirecta, a ciência produz benefícios que transformam por completo a vida humana. A segunda maneira é de carácter educacional — age sobre a mente. Embora pareça menos óbvia, esta segunda não é menos pertinente do que a primeira. (Einstein 2005: 144)

\section{CIÊNCIA E TÉCNICA}

Ciência e humanismo é um libelo contra o imperativo da técnica, associada de perto à hiperespecializaçáo da ciência já muito nítida a meio do século xx e ainda mais hoje. Ele confessa ter recolhido inspiração no filósofo espanhol seu contemporâneo José Ortega y Gasset, o autor em 1930 do livro A rebelião das massas (Ortega y Gasset 1989), onde considera alguns cientistas exemplo de gente das massas, de pessoas ignorantes, prontas a ser conduzidas a qualquer lado pela máo do Estado. Hoje em dia usa-se muito a palavra "tecnociência" para designar esse domínio da técnica sobre a ciência. Confesso que não costumo usar esse conceito, embora perceba a sua razão de ser. Se é verdade que a técnica precedeu a ciência ao longo da história (fez-se fogo antes de se conhecer a química da combustão e construíram-se máquinas a vapor muito antes de se conhecer a ciência termodinâmica), o 
certo é que modernamente, digamos desde meados do século XIX, quando se deu a segunda vaga da Revolução Industrial associada à electrificação das máquinas, que praticamente toda a técnica vem da ciência. Foi a teoria quântica, devida a Planck, Einstein, Bohr, de Broglie, Heisenberg, Schrödinger, Born e outros, que permitiu, após a Segunda Guerra Mundial, em 1949, a invenção do transístor, um dispositivo que mudou completamente as nossas vidas, uma vez que, hoje em dia, das televisóes às máquinas de lavar, dos telemóveis aos multibancos, dos automóveis aos avióes, tudo, em toda a parte, se encontra transistorizado de modo a automatizar o maior número possível de procedimentos (as máquinas que Ortega y Gasset tanto temia inundaram o mundo, embora tornando-se invisíveis e, por isso, aparentemente menos ameaçadoras). Claro que não partilho da aversão extrema de Ortega y Gasset à ciência, expressa entre outras frases violentas pelo seguinte excerto de $A$ rebeliáo das massas: "a ciência experimental tem progredido em grande medida graças ao trabalho de pessoas fabulosamente medíocres e até mesmo menos que medíocres" (Ortega y Gasset 1989: apud Schrödinger 1991:101).

Pode ser verdade que há pessoas medíocres na ciência, mas também as há, não sei se em maior ou menor medida, nas artes. A mediocridade, se é certo que existe, não é um atributo exclusivo da ciência. É oportuno citar a este respeito uma afirmação provocatória do já referido Hilbert sobre a relação da ciência com a tecnologia:

Ouve-se hoje muitas vezes falar de hostilidade entre ciência e tecnologia. Não creio, meus caros senhores, que isso seja verdade. Estou absolutamente certo que não é verdade. Não pode, de facto, ser verdade. Não têm, absolutamente nada a ver uma com a outra.

(apud Rosenfeld 1962: 57)

Percebe-se o que ele quer dizer com esta boutade. A ciência, mais do que mãe da tecnologia, é uma forma de humanismo. A sua verdadeira mola é a indagaçáo, a curiosidade, pelo que podemos perfeitamente falar de ciência pela ciência.

Schrödinger, no seu ensaio Ciência e humanismo, dirige-se a certa altura aos cientistas e professores de ciência: 
Nunca perca de vista o papel que a sua disciplina em particular tem no seio do grande espectáculo que é a tragicomédia da vida humana mantenha-se em contacto com a vida - não tanto com a vida prática mas com o pano de fundo ideal da vida, que é cada vez mais importante. E mantenha a vida em contacto consigo. Se não puder - a longo prazo - dizer a todas as pessoas o que tem estado a fazer, entáo o que tem feito foi inútil.

(Schrödinger 1999: 102)

E, quase no final do seu ensaio, regressa à questão inicial:

(...) considero a ciência como uma parte integrante do nosso esforço para responder à grande questão filosófica que abarca todas as outras, a questão que Plotino expressou de forma breve - quem somos nós? E, mais do que isso, considero que esta é não só uma das tarefas, mas a tarefa da ciência, a única que efectivamente tem importância.

(Schrödinger 1999: 132)

Como exemplo de ligação da ciência à necessidade filosófica dos homens, Schrödinger discute ao longo do seu ensaio, que tem o subtítulo A física no nosso tempo, a questão do contínuo e do descontínuo: a teoria quântica tinha trazido o descontínuo, embora os átomos modernos não fossem semelhantes aos de Demócrito de Abdera (ca. 460-370 a. C.). Discute sobretudo sobre a antiga questão do livre arbítrio e do determinismo. Se há determinismo, como na física clássica, então, a menos que surja qualquer solução engenhosa, o livre arbítrio parece prejudicado. Se não há determinismo como propóe a teoria quântica (o determinismo é apenas estatístico, isto é, só podemos aspirar a saber como se move uma onda de probabilidade), então o livre arbítrio fica ainda mais prejudicado. Conclui afirmando que uma mudança no conceito físico de causalidade náo podia ter qualquer consequência na ética humana, isto é, se a ciência estava ligada ao homem, o homem tinha preocupaçóes e anseios que náo podiam ser resolvidos pela ciência mais avançada. 


\section{O PAPEL DOS GREGOS}

Por que razão Schrödinger se dirigiu para a Antiguidade Grega para defender o valor da ciência? Por que ele via nos gregos um interesse pela ciência como procura do saber e uma unidade da ciência, como náo conseguia ver no século xx.

No texto que antecede Ciência e humanismo, A natureza e os gregos, Schrödinger fala da origem da ciência na Antiguidade Grega, defendendo a tese de que toda a nossa ciência vem dos gregos. A ciência é uma invenção dos gregos e herdámo-la dos gregos. Essa tese náo é original, tendo o autor prestado preito ao classicista britânico John Burnet: “(...) uma descrição adequada da ciência é afirmar que ela é 'pensar acerca do mundo à maneira dos Gregos' É por essa razão que a ciência nunca existiu senão nos seio de povos que alguma vez estiveram sob a influência da Grécia" (Burnet 1932: apud Schrödinger 1999). Também o prestou ao filósofo e classicista austríaco Thedor Gomperz: "Quase toda a nossa educação intelectual tem origem nos Gregos. Um conhecimento aprofundado destas origens constitui o pré-requisito indispensável para nos libertarmos da sua influência esmagadora" (Gomperz 1911: apud Schrödinger 1999).

Foi na Grécia antiga que surgiu a ideia da inteligibilidade da Natureza: esta pode ser compreendida, no sentido em que existem causas que originam certos efeitos. É atribuído a Tales de Mileto (ca. 624-ca. 546 a.C.) um dos exemplos mais antigos dessa atitude: ele propôs que um eclipse se deve à interposição de um astro diante da luz do Sol, não sendo por isso um acontecimento mágico, ou uma "brincadeira" dos deuses.

Preocupa-o, no início desse ensaio, o antagonismo entre ciência e religiáo, que ele diz compreender uma vez que a religião sempre procurou preencher os interstícios da ciência: quando havia um mistério por resolver atribuía-se a sua origem aos deuses (mais tarde a Deus). Mas, para os gregos, era possível discutir tudo o que acontecia no mundo. Um jovem, segundo Schrödinger, podia falar com Demócrito tanto sobre os átomos como sobre a Terra, a moral, a alma ou sobre os deuses:

Sou da opinião de que a filosofia da Antiguidade grega é atraente para nós nesta altura, porque nunca antes ou nunca desde entáo, em parte alguma 
do mundo, se estabeleceu algo de parecido com o sistema de conhecimento e de especulação tão avançado e tão articulado daquela época, sem a divisão fatídica que nos embaraça há séculos e que actualmente se tornou insuportável (...). Mas não havia qualquer limitação quanto aos temas acerca dos quais um homem instruído tinha a permissão de outros homens instruídos para dar a sua opinião.

(Schrödinger 1999: 25)

Schrödinger enumera os motivos para regressar ao pensamento holístico da Antiguidade. Para ele no mundo moderno a ciência estava afastada do homem, havendo que os aproximar:

E depois fico muito surpreendido por a imagem do mundo real à minha volta ser muito deficiente. Ela fornece muitas informaçôes factuais, ordena todas as nossas experiências de forma extraordinariamente consistente, mas é terrivelmente silenciosa no que diz respeito a todas as coisas que estão realmente próximas do nosso coração, as coisas que realmente têm importância para nós. Não nos consegue dizer uma única palavra acerca do vermelho e do azul, do amargo e do doce, acerca da dor física e do prazer físico. Não sabe nada acerca do belo e do feio, acerca do bom e do mau, acerca de Deus e da eternidade. A ciência por vezes faz de conta que responde a questôes nestes domínios, mas as respostas são muito frequentemente tão disparatadas que nos sentimos inclinados a não as aceitar como sérias. (Schrödinger 1999: 89)

A respeito do objectivo e do subjectivo, Schrödinger analisa problemas da física contemporânea, para a qual tinha dado contributos essenciais. O sujeito, que é o observador, póe-se de fora do mundo observado, num esforço de objectivação. Mas com a teoria quântica, pelo menos na acepção de escola de Copenhaga, havia uma interpenetração entre a pessoa do observador e a coisa observada. Ora, toda a tradiçáo da nossa ciência desde o tempo dos gregos provinha da separação entre sujeito e objecto, que ele considerava por isso basilar: 
(...) Náo pertencemos a este mundo material que a ciência idealiza para nós. Não estamos nele, estamos fora dele. Somos apenas espectadores. A razão pela qual acreditamos que estamos nele, que pertencemos à imagem, é porque os nossos corpos estáo nela; os nossos corpos pertencem-lhe. Não apenas o meu próprio corpo, mas os dos meus amigos e também o do meu cão, gato e cavalo, e de todas as outras pessoas e animais. E este é o meu único meio de comunicação com eles.

(...) Em particular, e mais importante, esta é a razão pela qual a mundivisão científica não contém em si própria quaisquer valores éticos, quaisquer valores estéticos, nem uma palavra acerca do nosso próprio âmbito ou destino, e pela qual não tem, se quiserem, qualquer Deus. De onde venho, e para onde vou?

A ciência não nos consegue explicar os motivos que fazem com que a música nos dê prazer, nem a razão ou o motivo de uma velha canção nos provocar o choro. (Schrödinger 1999: 89-90)

Quase no fim, afirma ao mesmo tempo a consciência dos limites da ciência e a confiança nas suas possibilidades:

O mundo é enorme, grandioso e belo. $\mathrm{O}$ meu conhecimento científico dos acontecimentos que se verificam nele abrange centenas de milhóes de anos. Porém, de outra forma, restringe-se manifestamente a uns pobres $70,80 \mathrm{ou}$ 90 anos que me são concedidos. Um pequeno espaço no tempo incomensurável ou mesmo nos milhôes e milhóes finitos de anos que aprendi a medir e a avaliar. De onde venho e para onde vou? Esta é a grande e insondável questão. A mesma para cada um de nós. A ciência não tem qualquer resposta para ela. Contudo, a ciência representa o nível mais elevado que jamais fomos capazes de descobrir para atingir o conhecimento seguro e incontroverso. (Schrödinger 1999: 90-91)

Eis o sábio Schrödinger, em toda a profundidade da sua sabedoria. Por um lado, estava consciente do profundo valor da ciência e, por outro, mostrava-se 
céptico de a ciência ser o único meio de chegar à compreensão do mundo. Remata o seu ensaio com uma expressão de confiança no futuro da espécie humana, que era também o futuro do pensamento:

a vida durará mais alguns milhóes de anos no futuro. E por causa de tudo isso sentimos que qualquer pensamento que possamos concretizar durante este tempo não terá sido em vão (Schrödinger 1999: 91).

De que serve o nosso pensamento baseado no que os outros pensaram antes de nós? Pois serve, muito simplesmente, para que os outros venham a pensar.

\section{CONSCIÊNCIA E VISÃO RELIGIOSA}

O autor de O que é a vida? (Schrödinger 1944, 1989) termina, após debater a origem material da vida, a discutir o que é a mente, ou se se quiser o espírito, a propósito da magna questáo do conflito entre determinismo e livre arbítrio, à qual haveria de voltar em Ciência e humanismo. No epílogo de O que é a vida o autor vai muito mais longe do que saber o que é a vida, ao avançar uma especulação sobre o que é a mente: avançou a tese, obviamente muito controversa (não admira que tenha sido alvo de uma tentativa de censura por parte de um clérigo irlandês que fazia a revisão de provas), de que a mente tem poder sobre os átomos, sendo assim o Eu uma espécie de Deus.

De algum modo, portanto, O que é a vida? foi premonitório do desenvolvimento das modernas neurociências. De facto, após a emergência da biologia molecular, seria a vez das neurociências conhecerem um percurso ascendente. Os segredos do cérebro deviam ser indagados, uma vez que o cérebro era, reconhecidamente, ao albergar a mente, o reduto da consciência. Na linha do epílogo de $O$ que é a vida?, Crick foi ele próprio estudioso das neurociências. No seu livro de 1994 intitulado A hipótese espantosa (Crick 1998), com o subtítulo $A$ busca cientifica da alma, defende que as neurociências já dispunham do instrumental para decifrar os fenómenos da consciência. Essa discussão prossegue nos dias de hoje. 
As especulações filosóficas de Schrödinger sobre a consciência encontram filiação não apenas no pensamento de alguns antigos gregos mas também em ideias do pensamento oriental, do hinduísmo, que pouco contacto teve com o pensamento grego e que pode, por isso, ser visto como complementar deste. As ideias schrödingerianas sobre a origem e significado da consciência haveriam de ficar mais nítidas no ensaio Espirito e matéria, publicado em 1958, que está colado a $O$ que é a vida? na edição portuguesa. Nesse livro, o autor fala da união das mentes humanas, formando uma espécie de espírito universal, Deus se se quiser. É muito claro a respeito dessa consciência universal: "Existe, obviamente, só uma alternativa, ou seja, a unificação dos espíritos ou consciências. A sua multiplicidade é apenas aparente, na verdade existe apenas um espírito" (Schrödinger 1989: 126).

$\mathrm{Na}$ continuidade da ideia da unidade biológica, revelada pelo código genético, atreve-se, portanto, a afirmar que o espírito é também universal. Se já em $O$ que é a vida? tinha afirmado que a consciência individual não devia ser mais do que uma forma da consciência global que impregnava todo o Universo, essa ideia sai claramente reforçada em Espirito e matéria. Está aqui muito próximo da esfera da religiáo. A questáo da religiáo de Schrödinger é particularmente interessante. Originário de um país católico e existindo na sua família uma linha de tradiçáo luterana, ele afirmou-se várias vezes ateu. Mas, mesmo assim, foi um ateu muito particular, atraído por uma certa forma de panteísmo. Fala no seu texto A natureza e os Gregos da:

questão da grande Unidade — o Ente único de Parménides — da qual todos nós de alguma forma fazemos parte, à qual pertencemos. O nome mais popular para ela na actualidade é Deus, com um “D” maiúsculo. A ciência é, normalmente, estigmatizada com a noção de que é ateísta. Depois de tudo o que dissemos este facto não é surpreendente. Se a mundivisão da ciência nem sequer contém o azul, o amarelo, o amargo e o doce — a beleza, o prazer e a piedade —, se a personalidade é excluída por consenso, como é que poderia conter a noção mais sublime que se apresenta perante a mente humana? (Schrödinger 1999: 90) 
Schrödinger continuou a sua jornada em busca do sublime. No seu livro final Meine Weltansicht ("A minha visão do mundo"), de 1961, ano da sua morte e portanto uma espécie de testamento intelectual, entra declaradamente no campo das filosofias orientais que já antes o tinham seduzido, em particular o Vedanta do hinduísmo: "O Vedanta ensina que a consciência é singular, que todos os acontecimentos se passam numa só consciência universal e que não há uma multiplicidade de eus" (Schrödinger 1961: 5, trad. do autor).

O espírito, sendo um, está por todo o lado. Tal como acontecia com o seu amigo Einstein (Fiolhais 2005), a visão de um Deus pessoal, como aparece nas "religióes do livro", parecia-lhe demasiado naïve, embora admitisse a existência, numa forma pouco comum, de um ente transcendente. Porém, não se pode deixar de considerar Schrödinger como um homem religioso, uma vez que ele, reconhecendo a necessidade de transcendente, o procurou até ao fim da vida.

\section{AS HUMANIDADES E AS CIÊNCIAS NO MUNDO DE HOJE}

Que podemos dizer hoje sobre o legado de Schrödinger? A sua equação mantém-se válida, sendo a base, por exemplo, de poderosas simulaçôes moleculares que permitem por exemplo obter novos medicamentos. A descrição probabilística da realidade, negada por Einstein e Schrödinger, continua a prevalecer, à falta de melhor. O genoma humano foi já completamente sequenciado e estão todos os dias a ser estabelecidas relaçóes com enfermidades. O problema da consciência, pesem embora os enormes avanços das neurociências, permanece por resolver. E, do ponto de vista da filosofia, se há contribuiçôes, sempre acumuladas, da física, da química e da biologia, o certo é que as grandes inquietaçôes continuam.

Hoje, passados 53 anos sobre a morte de Schrödinger, num mundo onde a ciência, sempre íntima da técnica, continuou a crescer, multiplicam-se as queixas sobre o défice das humanidades. Vivemos num mundo impregnado pela ciência, onde a ciência está invisível. E onde a compreensão da ciência é manifestamente escassa, limitada a alguns especialistas, poucos deles imitando Schrödinger no esforço de divulgação. Grandes questôes filosóficas enfrentadas por ele, como o determinismo e o livre arbítrio, a consciência humana, 
a existência de Deus, continuam a colocar-se no mundo de hoje. E elas clamam, hoje como ontem, pela unidade dos saberes.

A ciência é vista com alguma desconfiança pela gente das humanidades, tal como no tempo de Ortega y Gasset. Creio que há que quebrar essa divisão, afirmando uma e outra vez, as vezes que forem precisas, mostrando com exemplos da história, que a ciência, o conhecimento, é humanismo. Conheço e apoio no essencial o discurso em defesa das humanidades, feito, entre nós, por exemplo entre outros, por Vítor Aguiar e Silva, em As humanidades, os estudos culturais, o ensino da literatura e o a politica de lingua portuguesa: "As Humanidades, tanto as clássicas como as modernas, têm sofrido ao longo do século xx uma prolongada e perturbadora crise de identidade e legitimidade disciplinares" (Silva 2010: 71).

Não raro, a supremacia da técnica é considerada responsável por essa crise. Por vezes, fala-se também do primado das ciências exactas e naturais em detrimento das ciências sociais e humanas. Na linha de Schrödinger, devo dizer que o défice de humanidades nos dias de hoje é o défice de todas as ciências, quer dizer, o défice da unidade da ciência, de comunicaçóes entre os seus ramos. Precisamos não só de mais ciência como também de melhor ciência. E para isso é mister um melhor ensino das ciências, todas as ciências. Se as línguas gregas e latinas desaparecem dos currículos escolares em Portugal, com prejuízo dos estudos clássicos, também a física quântica quase não aparece nos liceus e, nas universidades, está acantonada nos cursos de física e de química. Só o diálogo entre as ciências, que deve começar por um diálogo entre os cientistas, só um diálogo entre as ciências e outras actividades humanas (ver os meus ensaios sobre o diálogo com as artes, Fiolhais 1994, 2008, 2013; e sobre o diálogo com a religião, Fiolhais 2005, 2011, 2014) poderão minorar o nosso défice da humanidade. As universidades, fazendo jus ao nome, deveriam ser um dos primeiros palcos a pôr em cena esse diálogo. 


\section{CARLOS FIOLHAIS}

\section{BIBLIOGRAFIA}

Burnet, John (1932). Early Greek Philosophy. 4. ${ }^{\mathrm{a}}$ ed. London: Macmillan and Co.

Chandrasekhar, S. (1987). Truth and Beauty. Aestetics and Motivations in Science. Chicago: The University of Chicago Press.

Crick, Francis, (1998). A hipótese espantosa, busca cientifica da alma. Trad. Joaquim Nogueira Gil. Lisboa: Instituto Piaget.

Einstein, Albert (2005). Como vejo o mundo, a ciência, a religião e o mundo. Trad. José Miguel Silva, Ruth San Payo. Lisboa: Relógio d’Água.

Fiolhais, Carlos (1994), "Os Jardins Secretos de Mandelbrot", Universo, computadores e tudo o resto, Lisboa: Gradiva, 87-110.

Fiolhais, Carlos (1997). "Saber e poder ou a modernidade de Sir Francis Bacon”, Tengarrinha, José Manuel, ed., Actas dos $3 .^{o s}$ Cursos Internacionais de Verão de Cascais (1 a 6 de Julho de 1996). Vol. 2. Cascais: Câmara Municipal de Cascais, 155-172.

Fiolhais, Carlos (2005). “Einstein e a Religiāo”, Estudos, Nova Série n. o 4, 323-329.

Fiolhais, Carlos (2008), "Imaginação, ciência e arte”, Biblos, 2. a série, 4, 3-16.

Fiolhais, Carlos (2011), "Em busca de sentido: Ciência e Religião", in Em buca de sentido: Ateísmo e crença na construção da pessoa que ama. Coimbra: Gráfica de Coimbra, 45-61.

Fiolhais, Carlos (2013), "Einstein: entre a Ciência e Arte”, Carvalho, J. C., coord., Arte e Ciências em diálogo. Coimbra: Grácio (ebook).

Fiolhais, Carlos (2014), "A ciência e o divino”, Borges, Anselmo, coord., Deus tem futuro? Lisboa: Gradiva.

Gomperz, Theodor (1911). Grieschische Denker. Leipzig: Veit and Comp.

Gribbin, John (2012). Erwin Schrödinger and the Quantum Revolution. London: Bantam Press.

Kumar, Manjit (2008). Quantum. London: Icon Books.

Moore, Walter J. (1992). Schrödinger, Life and Thought. Cambridge: Cambridge University Press. Moore, Walter J. (2003). A Life of Erwin Schrödinger. Cambridge: Cambridge University Press. Ortega y Gasset, José (1989). A rebelião das massas. Trad. Artur Guerra. Lisboa: Relógio D’Água. Piza, António de Toledo (2003). Schrödinger \& Heisenberg. A física além do senso comum. São Paulo: Odysseus.

Poincaré, Henri (1995) [1905]. O valor da ciência. Trad. Maria Helena Franco Martins. Rio de Janeiro: Contraponto.

Poincaré, Henri (1920). Science et Méthode. Paris: Ernest Flammarion. 
Rosenfeld, A. (1962). Langmuir. The Man and the Scientist. Oxford: Pergamon Press.

Sanchez-Rón, J. M. (1992). "A Man of Many Worlds, Schrödinger and Spain”, in Michel Bitbol, Olivier Darrigol, eds., Erwin Schrödinger. Philosophy and the Birth of Quantum Mechanics. Gif-sur-Yvette: Editions Frontières, 9-22.

Schrödinger, Erwin (1926). "Quantisierung als Eigenwertproblem”, Annalen der Physik, 384, 4, 361-376.

Schrödinger, Erwin (1944). What is Life? The Physical Aspect of the Living Cell. Cambridge: Cambridge University Press.

Schrödinger, Erwin (1949). Gedichte. Godesberg: Küpper.

Schrödinger, Erwin (1952). Science and Humanism. Cambridge: Cambridge University Press.

Schrödinger, Erwin (1961), Mein Weltansicht. Wien: Paul Zsolnay.

Schrödinger, Erwin (1989). O que é a vida? Espírito e matéria. Trad. M. L. Pinheiro. Lisboa: Fragmentos.

Schrödinger, Erwin (1996). Nature and the Greeks and Science and Humanism. Cambridge: Cambridge University Press.

Schrödinger, Erwin (1999). A natureza e os gregos e Ciência e humanismo. Trad. Jorge Almeida e Pinho. Lisboa: Ediçōes 70.

Silva, Vítor Aguiar e (2010). As humanidades, os estudos culturais, o ensino da literatura e o a politica de língua portuguesa. Coimbra: Almedina. 